\title{
BEHAVIOR OF METALS IN ORAL CAVITY
}

\author{
BY
}

\author{
KAZUO NAGAI*
}

Due to the poor economic considerations of the general public in Japan, various metal alloys other than precious metals are in wide use in the field of clinical dentistry. We have no doubt that they will be used in increased number in the future.

For this reason, it is a very important task to know as to how these alloys behave in the oral cavity where they are employed.

Being keenly interested in this matter, I have been conducting investigations on the subject for a long time. Now, at the 51 st Philippine Dental Congress held in Manila, I like to take this opportunity to make public some of these results so that they may prove useful for the work of the practicing dentists and as pertinent data for the specifications of dental materials at the same time. If they should prove of value to you, I feel my labors will have been amply rewarded.

TABLE 1

Silver alloys

\begin{tabular}{c|c|c|c|c|c|c|c}
\hline \multirow{2}{*}{$\mathrm{Ag}$} & $\mathrm{Zn}$ & $\mathrm{Cd}$ & $\mathrm{Sn}$ & Total & Use & \multicolumn{2}{|c}{ Clinical view } \\
\hline 68.15 & 9.61 & 0.2 & 17.82 & 95.78 & Inlay & $\triangle$ & \multicolumn{1}{c|}{$\begin{array}{c}\text { Physical } \\
\text { Property }\end{array}$} \\
\hline 64.87 & 17.24 & 0 & 16.98 & 99.09 & $\prime \prime$ & $\triangle$ & $\triangle$ \\
\hline 63.26 & 14.88 & 15.12 & 9.78 & 100.04 & $\prime \prime$ & $\bigcirc$ & $\triangle$ \\
\hline 60.13 & 4.07 & 10.06 & 20.75 & 100.01 & $\prime \prime$ & $\odot$ & $\triangle$ \\
\hline
\end{tabular}

TABLE 2

$\mathrm{Sn}-\mathrm{Sb}$ alloys

\begin{tabular}{c|c|c|c|c|c|c|c}
\hline $\mathrm{Sn}$ & $\mathrm{Sb}$ & $\mathrm{Cu}$ & $\mathrm{Zn}$ & Total & Use & \multicolumn{2}{|c}{ Clinical view } \\
\hline 72.26 & 26.96 & 0.031 & & 99.25 & Inlay & & $\begin{array}{c}\text { Physical } \\
\text { Property }\end{array}$ \\
\hline 77.43 & 21.28 & 0.031 & 0.42 & 99.16 & $\prime \prime$ & & $\triangle$ \\
\hline
\end{tabular}

* 永井一夫 : Prof. of dental technology, Nihon Univ. School of Dentistry (The above speech was read before the 51 st Philippine Dental Congress held in Manila in May 1959) 
TABLE 3

$\mathrm{Ni}-\mathrm{Cr}$ alloys (sheet)

\begin{tabular}{c|c|c|c|c|c|c|c|c}
\hline $\mathrm{Ni}$ & $\mathrm{Cr}$ & $\mathrm{Cu}$ & $\mathrm{Fe}$ & $\mathrm{C}$ & Total & Use & \multicolumn{2}{|c}{ Clinical view } \\
\hline Color & $\begin{array}{c}\text { Physical } \\
\text { Property }\end{array}$ \\
\hline 87.03 & 4.95 & 6.27 & 6.37 & 0.12 & 98.74 & Crown & $\bigcirc$ & $\triangle$ \\
\hline 84.76 & 5.50 & 4.49 & 0.33 & 0.12 & 95.20 & $\prime \prime$ & $\bigcirc$ & $\triangle$ \\
\hline 84.90 & 5.46 & 5.21 & 0.44 & 0.13 & 96.14 & $\prime \prime$ & 0 & $\triangle$
\end{tabular}

TABLE 4

18-8 steeis (wire)

\begin{tabular}{c|c|c|c|c|c|c|c}
\hline \hline $\mathrm{Ni}$ & $\mathrm{Cr}$ & $\mathrm{Fe}$ & $\mathrm{C}$ & Total & Use & \multicolumn{2}{|c}{ Clinical view } \\
\cline { 5 - 7 } & & & & & & Color & $\begin{array}{c}\text { Physical } \\
\text { Property }\end{array}$ \\
\hline 8 & 18 & 74 & 0.12 & 100.12 & Clasp & $\odot$ & $\odot$ \\
\hline 8 & 16 & 76 & 0.061 & 100.061 & $\prime \prime$ & $\odot$ & $\odot$
\end{tabular}

TABLE 5

Co-Cr alloys

\begin{tabular}{c|c|c|c|c|c|c|c|c|c|c|c|c}
\hline \hline $\mathrm{Co}$ & $\mathrm{Cr}$ & $\mathrm{Ni}$ & $\mathrm{Fe}$ & $\mathrm{W}$ & $\mathrm{Mo}$ & $\mathrm{Cu}$ & $\mathrm{C}$ & Total & Use & \multicolumn{2}{|c|}{$\begin{array}{c}\text { Clinical view } \\
\text { Color }\end{array}$} \\
\hline 34.33 & $\frac{2}{20.45}$ & 16.05 & $\frac{22.89}{\text { Phopical }}$ \\
\hline 19.76 & 13.34 & 50.19 & 1.89 & 0.81 & 0.13 & 0.10 & 96.65 & Plate & $\bigcirc$ & $\bigcirc$ \\
\hline
\end{tabular}

TABLE 6

$\mathrm{Cu}$ alloys

\begin{tabular}{c|c|c|c|c|c|c|c}
\hline \hline $\mathrm{Cu}$ & $\mathrm{Zn}$ & $\mathrm{Al}$ & Others & Total & Use & \multicolumn{2}{|c}{ Clinical view } \\
\cline { 5 - 7 } & & & & & Color & $\begin{array}{c}\text { Physical } \\
\text { property }\end{array}$ \\
\hline 68.5 & 29.5 & 2 & - & 100 & $\begin{array}{c}\text { Inlay \& } \\
\text { Cast Crown }\end{array}$ & 0 & $\bigcirc$ \\
\hline 69.2 & 29 & 1.8 & - & 100 & $\prime \prime$ & $\bigcirc$ & $\bigcirc$ \\
\hline 52.5 & 46 & 0 & 1.5 & 100 & $\prime \prime$ & $\bigcirc$ & $\bigcirc$ \\
\hline 51.0 & 47 & 0 & 2.0 & 100 & $\prime \prime$ & $\bigcirc$ & $\bigcirc$
\end{tabular}

Now, from Chart I to Chart VI there are given kinds of dental alloys usually used in Japan and results of their chemical analyses. 
Chart I gives those of silver alloy. Contents of silver vary from 60 to $68 \%$. Of these various silver alloys, that of around $60 \%$ does not decolor in the oral" cavity. However, as to the tensile strength and elongation, they are not favorable. Therefore, its physical property can not be said to be perfect.

Chart II gives those of antimony and zinc alloy. Although it does not decolor in the oral cavity, its physical property is not good.

Chart III gives those of nickel-chrome alloy. The chief constituent is nickel which is about $85 \%$, the rest being chrome, copper and slight quantities of iron and carbon. It does not decolor in the oral cavity but it is difficult of malleation since it has a high tensile strength.

Chart IV gives the result regarding 18-8 steel for the clasp use. It does not decolor in the oral cavity, however it is disadvantageous in that it decreases in tensile strength when it is subjected to soldering.

Chart $\mathrm{V}$ shows the cobalt-chrome alloy. It is ideal for the full plate as well as partial plate. But it is impossible for a dentist to work on them in his own laboratory.

Chart VI gives the copper alloy. This alloy which has been hitherto in use is compounded of $70 \%$ copper and $30 \%$ zinc, with some addition of alminum. For this reason, it generates 'the de-zinc phenomenon' in the oral cavity and its surface becomes quite rough with small holes in it. The recent discovery has produced a type of copper alloy which contains more amount of zinc so that it may give the $\beta$ system and also some precious metal is added to it. It is being ased with good results.

\section{TABLE 7}

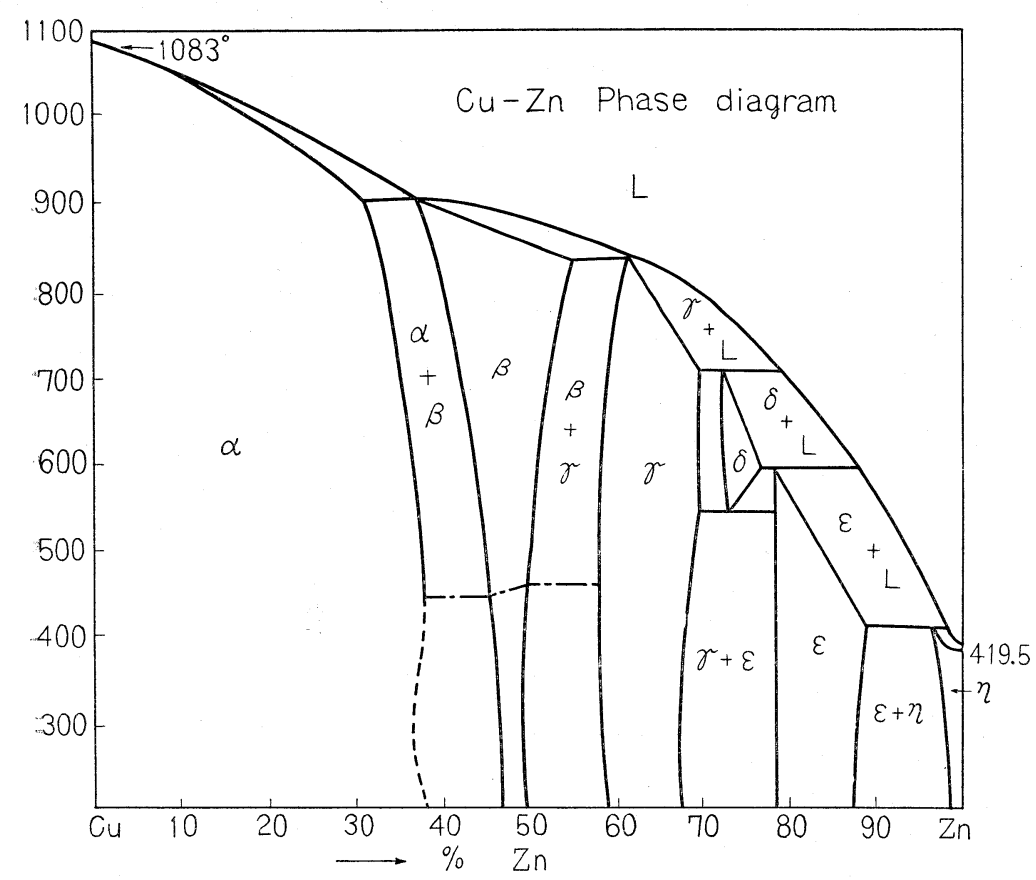


A

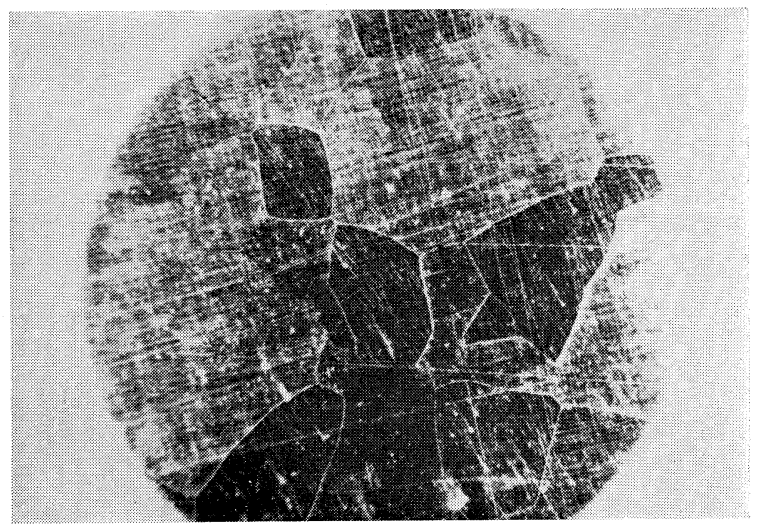

$\mathrm{B}$

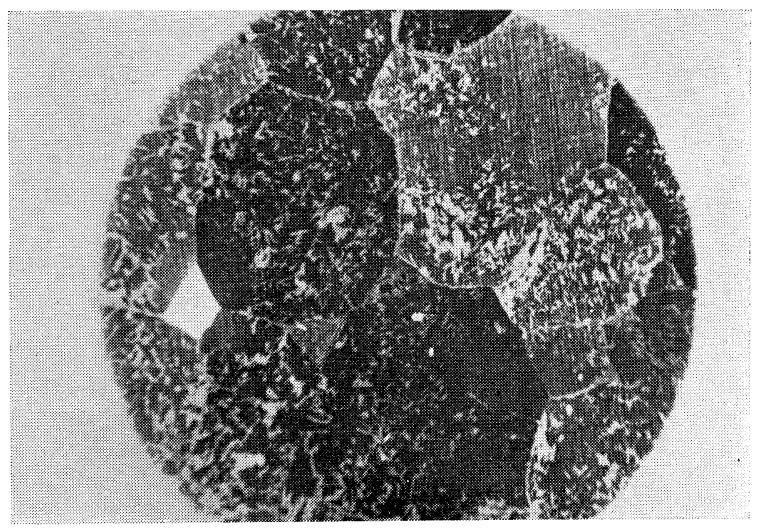

$\mathrm{C}$

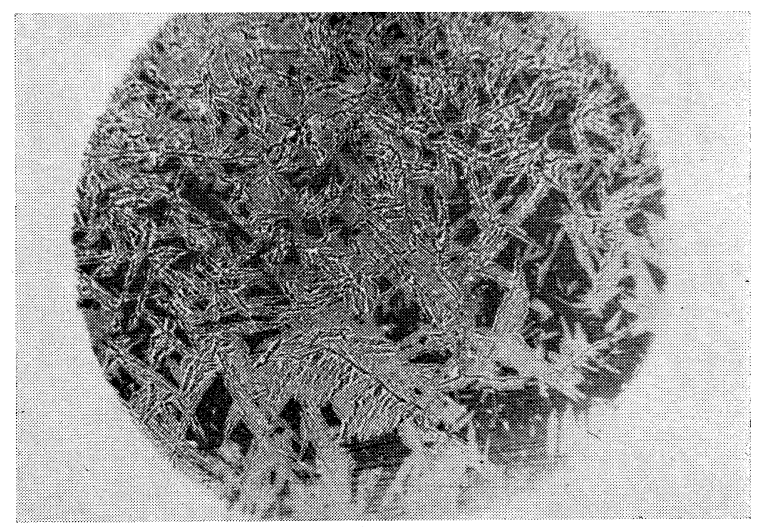

Chart VII indicates the alloys of copper and zinc family. Those which were used previously contained 70\% of copper and 30\% of zinc, and it gave the $\alpha$ system to this degree. Those of recent discovery contain the increased amount 
of zinc and gives the $\beta$ system to this degree.

This 7A is the $\alpha$ system, the next one which is $7 \mathrm{~B}$ is the $\alpha$ and $\beta$ system combined and the last one is the $\beta$ system.

It goes without saying that it is very important that we dentists should know how these alloys behave in the oral cavity, that is to say, how they are affected by corrosion. For this reason, we have conducted three experiments on them in test tubes.

Chart VIII gives a diminution per centimeter square on the daily basis of an immersion in $0.05 \%$ of hydrochloric acid, $1 \%$ of lactic acid and $1 \%$ of table salt at the temperature of 37 centigrade.

TABLE 8

Corrosion by effect of Reagents $\mathrm{mg} / \mathrm{cm}^{2} /$ day

\begin{tabular}{c|c|c|c}
\hline \hline Reagents & HCl $0.05 \%$ & Lactic acid $1 \%$ & NaCl $1 \%$ \\
\cline { 1 - 2 } Alloys & $0.83 \mathrm{mg}$ & $0.49 \mathrm{mg}$ & $0.17 \mathrm{mg}$ \\
\hline Sn-Sb Alloy & $1.20 \mathrm{mg}$ & $0.7 \mathrm{mg}$ & $0.11 \mathrm{mg}$ \\
\hline $\mathrm{Cu}$ Alloy & $1.01 \mathrm{mg}$ & $0.7 \mathrm{mg}$ & $0.07 \mathrm{mg}$ \\
\hline Ni-Cr Alloy & $0.41 \mathrm{mg}$ & $0.31 \mathrm{mg}$ & $0.01 \mathrm{mg}$
\end{tabular}

Chart IX gives a daily diminution per centimeter square of an immersion in every-day beverages such as apple juice, orange juice and Bireley's orange juice. When it is compared with the result given by the Chart VIII, we find that corrosion by these drinks is very slight.

TABLE 9

Cyrrosion by Daily Beverages $\mathrm{mg} / \mathrm{cm}^{2} /$ day

\begin{tabular}{c|c|c|c}
\hline Reagents & $\begin{array}{c}\text { Apple Juice } \\
\mathrm{pH} \mathrm{4.11}\end{array}$ & $\begin{array}{c}\text { Orange Juice } \\
\mathrm{pH} 2.65\end{array}$ & $\begin{array}{c}\text { Bireley's Juice } \\
\mathrm{pH} 2.76\end{array}$ \\
\hline Alloys & $0.007 \mathrm{mg}$ & $0.04 \mathrm{mg}$ & $0.05 \mathrm{mg}$ \\
\hline Ag Alloy & $0.01 \mathrm{mg}$ & $0.06 \mathrm{mg}$ & $0.07 \mathrm{mg}$ \\
\hline Sn-Sb Alloy & $0.007 \mathrm{mg}$ & $0.04 \mathrm{mg}$ & $0.07 \mathrm{mg}$ \\
\hline $\mathrm{Cu}$ Alloy & 0 & $0.02 \mathrm{mg}$ & $0.01 \mathrm{mg}$ \\
\hline Ni-Cr & 0 & 0 & 0 \\
\hline Co-Cr & 0 & 0 & 0 \\
\hline $18-8$ & & &
\end{tabular}

As the second experiment, we prepared the artificial saliva in order to simulate the conditions of an actual oral cavity. Chart $\mathrm{X}$ gives the composition of this artificial saliva. 
TABLE 10

\begin{tabular}{c|c}
\hline Composition of Artificial & \multicolumn{1}{c}{ Saliva } \\
\hline $\mathrm{KCl}$ & $2.4 \mathrm{~g}$ \\
\hline $\mathrm{Ca}_{3}\left(\mathrm{PO}_{4}\right)_{2}$ & $0.6 \mathrm{~g}$ \\
\hline $\mathrm{K}_{2} \mathrm{SO}_{4}$ & $0.9 \mathrm{~g}$ \\
\hline $\mathrm{K}_{2} \mathrm{HPO}_{4}$ & $1.4 \mathrm{~g}$ \\
\hline $\mathrm{Na}_{3} \mathrm{PO}_{4}$ & $0.8 \mathrm{~g}$ \\
\hline $\mathrm{Albumin}$ & $5.0 \mathrm{~g}$ \\
\hline $\mathrm{H}_{2} \mathrm{O}$ & $1000 \mathrm{cc}$
\end{tabular}

The dental alloys were immersed in: this artificial saliva for a period of 24 hours, during which they were in turn placed in the soy sauce of Kikkoman brand for 6 minutes, in the ordinary sauce for 6 minutes, and in Bireley's orange juice for 6 minutes, 18 minutes altogether. In other words, the metals were placed in the artificial saliva for 23 hours and 42 minutes. This process was repeated for 35 days. Reference is made to Chart XI.

The result is given on Chart XII. When the diminished amount during the

TABLE 11

Process of immersion test

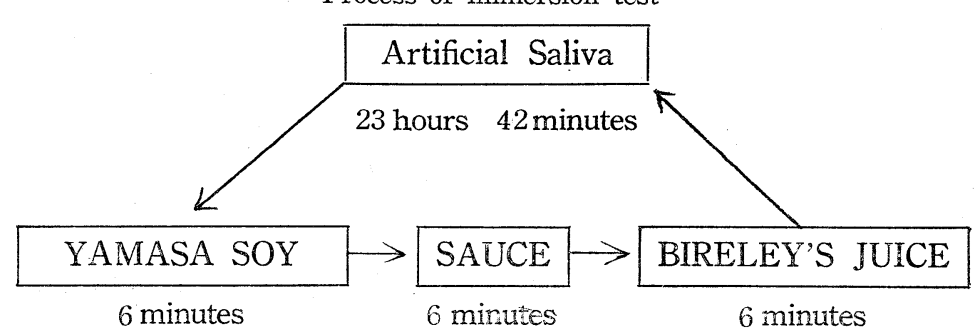

TABLE 12

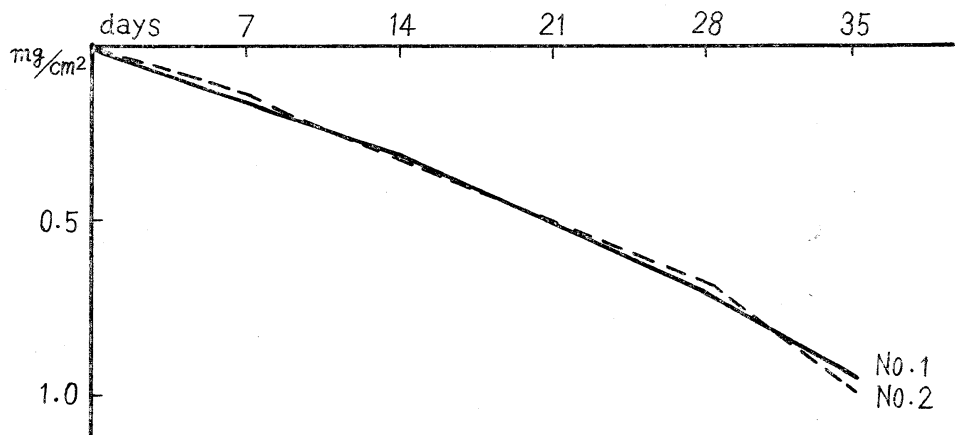

Decreased Quantities $\mathrm{mg} / \mathrm{cm}^{2}$

\begin{tabular}{|c|c|c|c|c|c|c|}
\hline & 7 days & 14 days & 21 days & 28 days & 35 days & $\mathrm{mg} / \mathrm{cm}^{2} /$ day \\
\hline $\begin{array}{c}\text { Cu-alloy } \\
\text { No. } 1\end{array}$ & 0.146 & 0.271 & 0.479 & 0.667 & 0.896 & 0.0256 \\
\hline $\begin{array}{c}\text { Cu-alloy } \\
\text { No. 2 }\end{array}$ & 0.137 & 0.275 & 0.457 & 0.640 & 0.915 & 0.0261 \\
\hline
\end{tabular}


total 35 days is calculated in terms of one centimeter square milligram per day, the copper alloy No. 1 is 0.075 milligrams and the copper alloy No. 2 is 0.066 milligrams.

Then, our interest will be, how is the diminution in the actual oral cavity? As you see from Chart XIII, a upper jaw plate was made by means of cast and the whole surface was wrapped up by zinc foil, the surface being measured after the foil was evened. This plate was installed in the human oral cavity for 35 days and the weight of it was measured on the weekly basis. Chart XIV gives these results.

In closing my report, I like to summarize the highlights of the present study:

1. Alloys of various kind dissolve themselves slightly in the oral cavity. The copper alloy in which the corrosion is found to be highest diminishes daily 0.034 milligrams per contimeter. This amount is negligible, for it is only one-hundred-fiftieth of copper which the human body requires every day.

2. In looking into the corrosion of these metals in test tubes, a good method seems to be one in which the artificial saliva and a few every-day beverages are employed. The way the metals decolor in this method is similar to the actual oral

Fig. 13

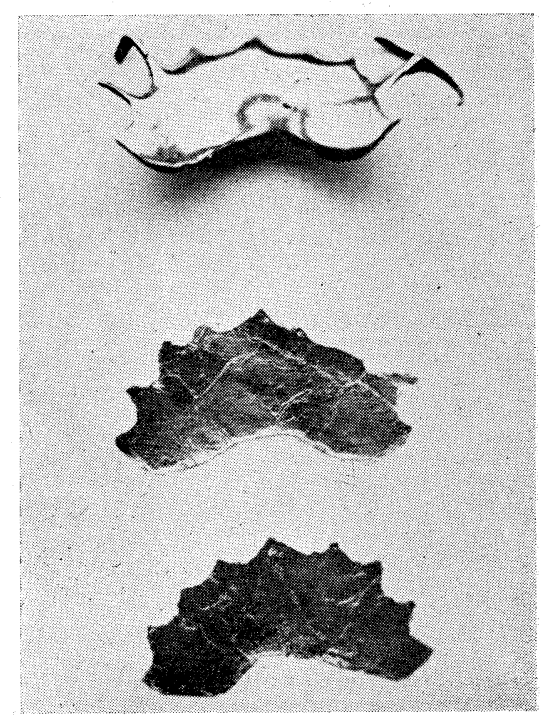

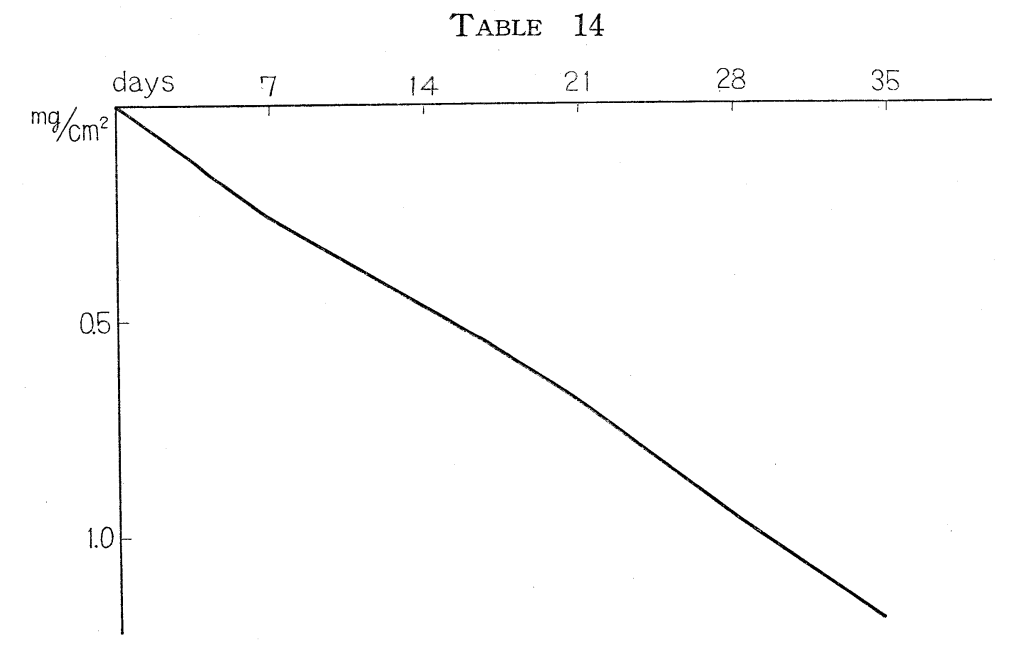

\begin{tabular}{|c|c|c|c|c|c|c|}
\hline Number of days & 7 & 14 & 21 & 28 & 35 & $\mathrm{mg} / \mathrm{cm}^{2} / \mathrm{day}$ \\
\hline $\begin{array}{c}\text { Corrosively } \\
\text { decreased amount }\end{array}$ & $0.25 \mathrm{mg}$ & $0.48 \mathrm{mg}$ & $0.68 \mathrm{mg}$ & $0.94 \mathrm{mg}$ & $1.22 \mathrm{mg}$ & $0.034 \mathrm{mg}$ \\
\hline
\end{tabular}


conditions.

3. An immersion test with the hydrochloric acid, lactic acid and table salt is non-significant, for it differs greatly from the actual oral conditions.

4. The copper alloy of new type diminishes daily 0.034 milligrams per centimeter and it does not exercise any harmful effect. 